\title{
An Examination of the Effectiveness of the Implementation of Safety and Security Measures at Public Schools in South Africa
}

\author{
Mgadla Isaac Xaba \\ North-West University: Vaal Triangle Campus, School of Educational Sciences, Vanderbijlpark \\ Gauteng Province, South Africa \\ Email: Ike.Xaba@nwu.ac.za
}

Doi:10.5901/mjss.2014.v5n27p490

\begin{abstract}
School safety and security continue to demand attention at schools worldwide and in particular, South Africa, where numerous events expose schools as unsafe environments. Legislation and various policy directives do provide for safety measures to be enacted at schools. Added to legislative provisions, are best practices in safety and security, which should engender the implementation of legislative provisions and behavioural practices aimed at keeping schools safe and secure. With this study, I explored the effectiveness of the implementation of safety measures at schools. Data collection was done through a quantitative survey of teachers and qualitative interviews of school principals. Findings indicate a mix of effective implementation with numerous challenges on other aspects of safety and security measures at schools. Though recommendations point mainly to ensuring the implementation of existing safety and security measure and best practices, the main recommendation points to the role of departmental officials who must play an effective oversight role and most importantly, support and development roles, including making sure that school governing bodies consider school safety as a school functionality lever and include it in their school strategic development planning.
\end{abstract}

Keywords: school safety measures; natural surveillance, access control; territoriality; physical school environment; psychosocial school environment.

\section{Introduction and Rationale}

School safety and security continue to be major issues demanding attention at schools worldwide and in particular, South Africa, where numerous events expose schools as unsafe environments. Recent media reports and numerous studies highlight this feature of schooling in the country. Whereas such events were almost entirely associated with township schools, it is becoming clear that safety-threats at schools are becoming widespread and even include the previously 'safe and secure' town-suburban schools, which were, pre-democracy, reserved for whites only. These occurrences go against the universally accepted norm that advocates school safety and security as a condition that advances the constitutional right of learners "to an environment that is not harmful to their health and well-being" and "to be protected from neglect, abuse or degradation" as enshrined in Sections 24(1) and 28(1) of the Constitution of the Republic of South African (Republic of South Africa, 1996a).

The right to safety and security is also extended to all people connected to the school, notably staff. Masitsa (2011) makes a compelling point in this regard and argues that "since the learner and the teacher operate in the same school environment, what applies to the learner with regard to safety also applies, mutatis mutandis, to the teacher" (p. 167) and further points out that "It is unequivocal logic that the teacher cannot provide adequate safety and security for the learner if he/she is not safe at school" (p. 167). For this reason, the right to safety for staff is also covered by Section 10 of the Constitution which states that everyone has inherent dignity and the right to have his/her dignity respected and protected and Section 12(a) which stipulates inter alia, that everyone has the right to be free from all forms of violence from either public or private sources.

Considering the legislative stipulations alluded to above, it is clear that the law does provide for safe and secure schools. However, in light of incidents that persistently undermine safety and security as reported widely in the media and numerous studies, a question that arises is: how effective is the implementation of safety measures at schools? The intent of this study therefore, was to explore the effectiveness of the implementation of safety measures at schools. 


\section{Literature Review}

This section exposes the essence of school safety and security measures and best practices in school safety and security.

\subsection{School Safety and Security Measures}

School safety and security is premised on two main dimensions, namely, legislative provisions, which are prescriptive in nature; and best practices in schools safety and security, which are dependent on what people do in terms of implementing legislative provisions and establishing structures and social behaviours that promote safety and security. Legislation subsequent to the Constitution spells out measures aimed at upholding the right to safe and secure schools. To this end, Section 60(1) of the South African Schools Act (Republic of South Africa, 1996b) relates specifically to school safety and places a liability on the state "for any damage or loss caused as a result of any act or omission in connection with any educational activity conducted by a public school and for which such public school would have been liable but for the provisions of this section". This, according to Naidu, Joubert, Mestry, Mosoge and Ngcobo (2008), implies the "liability of the state for any damages or disadvantages that learners may suffer as a result of accidents that take place at school or during activities outside the school" (p. 27). Accordingly, these authors make the point that the school has a legal duty to ensure the safety of learners, which is known as the duty of care.

Furthermore there exist numerous legislative pieces within which school safety is located and entail the safety of both the physical and psychosocial school environments. Government Notice 1040 (Department of Education, 2001), states that "No person shall, without permission of the principal or HOD, enter into any public school premises in respect of which a direction has been issued" and thus addresses matters pertaining to access to public schools. Government Gazette No. R1128 (Department of Education, 2006), amends the Schools Act and proclaims Amendment Regulations for Safety Measures at Public Schools. Section 2 thereof proclaims that a public school must take measures to ensure the safety of learners during any school activity, including insuring against accidents, injuries, general medical expenses, hospitalisation and theft that may occur, depending on the availability of funds; ensuring, where reasonably practicable, that learners are under the supervision of an accompanying teacher at all times; and requesting parents or other adults to assist in the supervision of learners. Section 8(f) addresses in particular, measures for emergencies and fire procedures including emergency evacuations, installation and maintenance of fire extinguishers and alarms as well as the conduct of fire drills. Finally, the proclamation of Regulations for Safety Measures at Public Schools, in terms of Section 61 of the Schools Act as amended by Government Gazette No. 30637 (Department of Education, 2007), declares schools as drug and dangerous objects-free zones. Section 2 specifically addresses a number of measures, and directs that:

- no person may bring a dangerous object or illegal drug into school premises or have such object or drug in his or her possession in school premises or during any school activity within or outside school premises;

- a learner may be subjected to a random body search;

- any dangerous object or illegal drug that has been seized must be - clearly and correctly labeled with the full particulars of the learner in whose possession it was found and handed over to the police immediately; and

- the principal or his or her delegate may at random administer a urine test to a learner who is reasonably suspected of using illegal drugs, after taking into account all relevant factors.

In addition to legislated school safety measures, there are best practices, which mainly concern what people do to ensure the safety of the school environment. It can be argued in this regard, that best practices in school safety and security form the basis for implementing regulated safety measures exposed above and are aimed at the safety and security of the school environment, which consists of the physical and psychosocial environmental factors.

The physical environment consists of buildings, grounds and service systems and serves the purpose of forming a safety envelope around the entire school environment, thereby presenting safety and security to persons and all the school's "usables" and resources. Best practices in safety and security with regard to the physical environments include the upkeep and maintenance of buildings, grounds and service systems. The aim thereof is, firstly, to ensure that all facilities within the school are in good working order and do not present any potential hazards to occupants and users (U.S. Consumer Product Safety Commission, 2010). For this reason, regular maintenance in the form of routine, corrective, predictive and preventive practices are crucial best practices (Nyman \& Levitt, 2006, p. 8). Secondly, the aim is to ensure that surroundings, perimeter fencing, playgrounds, vehicular routes and parking areas, landscaping and signage serve the purpose of ensuring effective and easy-to-implement access control and surveillance of the school environment including the safe use and condition of service systems like electricity, fire control, plumbing, drainage and 
sanitation, emergency systems and procedures and waste management (Western Cape Education Department, 2014; Hanover Research, 2013a; Brunner \& Lewis, 2005, p. 24; UNESCO, 2004, p. 1; San Diego County Office of Education, 2003; Florida Department of Education, 1993, p. 4).

The Scandinavian Schools of Brussels (Undated) define the psychosocial environment as "the interpersonal relationships in the school, the social environment and how the students and the staff interact with each other" and makes the point that the "psychosocial environment is also about the students' experience of the learning situation". For this reason, the psychosocial environment is invariably "grounded in the attitudes, values, beliefs, and behaviours of all who live and learn in the hallways, athletic venues, and classrooms of a school" (The Society of State Leaders of Health and Physical Education, 2014). Therefore, the psychosocial environment consists of, according to Voices \& Choices (2003) cited by Xaba (2014), social behavioural practices that include providing a friendly, rewarding and supportive atmosphere, supporting cooperation and active learning, forbidding physical punishment and violence, not tolerating bullying and harassment, valuing the development of creative activities, connecting school and home life, promoting equal opportunities and participation and identifying positive characteristics of the school environment. Xaba (2014) makes the point that aspects of the psychosocial environment listed above "will almost always be contained in school policies and codes of conduct" which "give a legal effect to the school's own safety and security measures". It can therefore be concluded that the psychosocial school environment plays a crucial role in learners' experiences of the school. This makes the school environment a critical aspect of these experiences and thus requires vigilance and monitoring in order to ensure that unbecoming and potentially hazardous behaviours among learners and adults at school are timely noted and dealt with. Natural surveillance of the school environment is thus a necessary aspect of facilitating this.

Natural surveillance refers to being able to see and to observe what happens in and around the school, especially the school campus and thus natural surveillance involves placing physical features to maximize visibility (Schneider, 2010). Desyllas, Connoly and Hebbert (2003) relate to Newman (1972) who defines natural surveillance as "the capacity of the physical environment to provide surveillance opportunities for residents or their agents" (p. 644). Natural surveillance thus exhibits two dimensions: an act of being aware of the school's surroundings and the capacity or the placement of physical features in the school environment in such a way that safety measures can be implemented easily. For example, the placement of the playing ground and their concomitant amenities must be such that they can be monitored and observed to prevent or be aware of safety threats to learners. In this regard, Desyllas et al. (2003, p. 644) point out two types of natural surveillance: the surveillance provided by occupants of buildings and the surveillance provided by members of the public on the street. This suggests strongly then that natural surveillance measures can best work out and be implemented in school environments that are also neighbourhood-friendly. To this end, Schneider (2010) argues that solid walls, tall shrubs, parked cars, outbuildings, sculptures, large signs, and other obstacles can block natural surveillance.

According to Schneider (2010), access control "is the ability to decide who gets in and out of your school." Therefore access control refers to the physical guidance of people coming and going from a space or as Thomas (2013) explains, a "system for enabling or preventing people from entering or exiting a location, whether a whole site or a single room or cupboard". American Clearing House of Educational Facilities (undated) defines access control as "guiding people with signage, well-marked entrances and exits, and landscaping while limiting access to certain areas by using real or symbolic barriers". In essence, access control occurs through either natural or constructed components and according to Public Schools of North Carolina State Board of Education (2013), consists of such school environmental features as the campus perimeter, entrances and exits and other entry points, visitor parking and visitor screening. Therefore implementing safety measures with regard to access control entails inter alia, maintenance of the school's perimeter fencing, channelling, directing and screening visitors to the administration office, regulating and controlling vehicular traffic, displaying clear and visible signage for providing directions and regulations to be observed and ensuring that egress and ingress points are clearly marked and designated with appropriate personnel and that out-of-bound areas are clearly demarcated. These measures, where necessary and practicable, could include technology-based security gadgets such as surveillance cameras, closed-circuit television systems, weapon detection systems and entry and exit control systems like key cards (Hanover Research, 2013b).

Territoriality relates to clearly delineating space, expressing pride and ownership, and creating a welcoming environment (American Clearing House of Educational Facilities (undated). Public Schools of North Carolina State Board of Education (2013) defines territoriality as "the personalization of space that might be available to any person in order to emphasize the perception of ownership". Territoriality can thus be seen as creating a sense of ownership of the school's space through the use of measures that assign utilisation of spaces to groups or individuals in such a way that they identify and personalise such spaces. In this regard, Schneider (2001, p. 2) identifies signs restricting access, directing visitors to the office, or posting campus closing times as the most straight forward examples of territoriality. 
It can be surmised that natural surveillance and territoriality form the gateway to effective access control and can thus be considered essential in the implementation of safety measures at schools. In fact, both the legislative provisions and best practices for school safety and security are manifested in school activities that include management aspects, surveillance and access control, service systems and the psychosocial elements of school environments.

\section{Method}

A concurrent mixed method design was used for data collection. This was for pragmatic reasons in that I sought to use data collection methods that, as espoused by Ivancovic, Creswell and Plano Clark (2007) would "work best for understanding the research problem" (p. 15). For this reason, I used the quantitative survey and qualitative interviews as a way of "providing a more comprehensive and complete picture of data by converging data analysis methods and offsetting strengths and weaknesses" of both quantitative and qualitative methods (McMillan \& Schumacher, 2006, p. 405).

The empirical survey was conducted at schools in the Gauteng Province's Sedibeng districts of the Gauteng Department of Education. Firstly, a questionnaire survey was used to collect data. The questionnaire comprised a section for demographic data and the section with items dealing with school safety and security categories namely, the management aspects, surveillance of and access control to the school environment, service systems and practices and psychosocial environments of schools as dimensions. To establish the reliability and validity of the questionnaire, the research question, categories of school safety and security as derived from the literature review were used as starting points to ensure that the content and constructs used in relation to school safety and security were appropriate and ensured that the questionnaire items measured what they were supposed to measure (Struwig \& Stead, 2007, p. 139). The questionnaire was pre-tested with a sample of teachers $(n=80)$ in the Sedibeng West District, and based on the responses, the necessary local linguistic adaptations were made for the final questionnaire. All questionnaire items yielded a Cronbach Alpha coefficient of 0.928980 and an average inter-item correlation of 0.212226 . The individual categories of questions measuring the construct "school safety and security measures" yielded Cronbach Alpha values of 0.791910 for management aspects, 0.722765 for surveillance and access control, 0.803456 for service systems and practices and 0.847476 for the psychosocial environment and corresponding average inter-item correlations of 0.242871 , $0.225504,0.262956$ and 0.392204 respectively for the categories, which indicated high reliability.

Secondly, interviews with 15 principals purposely selected were conducted on some aspects of the aforementioned categories. The principals were selected in such a way that they represented the demographics of schools in terms of town-suburban schools and township schools. The former schools were, before 1994 exclusively for Whites and were located in Whites only suburbs. Currently these schools are multicultural and in most instances, have more Black learners than White. The latter schools were exclusively for Blacks and still serve Black learners, although this is by choice and not segregated legally. The town-suburban schools, having been advantaged before 1994, are wellresourced and display many features of safety and security, while the township schools are largely under-resourced and display lack of many safety and security features. In fact, these schools are located in areas of the working class parents characterised by high unemployment and poverty levels.

The population for the study comprised 5449 teachers from 206 public schools in the Sedibeng districts of the Gauteng Department of Education (GDE). The sample consisted of teachers $(n=400)$ selected through simple random sampling in line with Leedy and Ormrod's (2005, p. 221) assertion that for sampling purposes, beyond a certain point (approximately $\mathrm{N}=5 \mathrm{000}$ ), the population size is almost irrelevant, and a sample size of 400 is adequate. Of the questionnaires returned, 322 , representing $80.5 \%$ were usable which was considered an acceptable return rate (Delport, 2002, p. 172).

Quantitative data analysis involved a frequency analysis of responses according to four dimensions identified through the literature review, namely management aspects of school safety and security, surveillance systems and access control, service systems and practices and the psychosocial environment. These dimensions were used as a priori categories for the qualitative data (McMillan \& Schumacher, 2006, p. 368) and as such, data from interviews with principals were analysed by matching the responses to the same dimensions. The aim was to get clarity and insight on issues the questionnaire would not be able to address. This also served to enhance the trustworthiness of the data, including verbatim phrasing of data in participants' own words and member checks on the accuracy of the verbatim transcriptions (McMillan \& Schumacher, 2006, p. 325 \& p. 390).

Permission to conduct research at schools was granted by the Gauteng Department of Education. Interviews with the 15 principals were conducted at their schools. The necessary ethical standards were upheld, which included voluntary participation and informed consent and the right to withdraw and or not answer questions they felt uncomfortable with as 
well as the right to confidentiality and anonymity. The research results therefore do not refer to schools or respondents in any identifiable manner.

\section{Results}

Respondents to the questionnaire comprised $68.3 \%$ female and $31.7 \%$ males, mostly from township schools (82.3\%) and town-suburban schools (14.9\%). The majority of the respondents (74.6\%) had been teachers for between 10 and 30 years. Most respondents (66.5\%) were from schools with enrolments of between 600 and 1000 learners and most of them (60.9\%) were from schools with staff complements of between 20 and 40 . The array of demographic features of the respondents was helpful in providing data covering diverse school environments.

The first category sought to find out how effective management aspects of school safety and security were implemented at schools (Table 1).

Table 1: Data of the management aspect of school safety

\begin{tabular}{|c|c|c|c|c|}
\hline \multirow[t]{2}{*}{ Items } & \multirow[t]{2}{*}{ Questions } & \multirow{2}{*}{\multicolumn{2}{|c|}{$\begin{array}{cc}\text { Yes } & \text { No } \\
\% & \% \\
\end{array}$}} & \multirow{2}{*}{$\begin{array}{c}\text { Not sure } \\
\% \\
\end{array}$} \\
\hline & & & & \\
\hline 1 & Is there a school safety committee? & 72.4 & 23.6 & 4.0 \\
\hline 2 & Is there a school safety policy? & 67.1 & 28.2 & 4.7 \\
\hline 5 & Is there an incidents register where all disruptions and safety violations are recorded? & 45.0 & 52.8 & 2.2 \\
\hline 6 & Are violations of the law reported immediately to the police and the department? & 74.8 & 22.6 & 2.6 \\
\hline 7 & Are disruptive incidents analysed to identify trends of common school safety problems? & 45.0 & 49.7 & 5.3 \\
\hline 9 & Is staff trained in detecting weapons? & 8.1 & 89.4 & 2.5 \\
\hline 26 & Is there an emergency team organized to implement emergency plans? & 25.8 & 71.7 & 2.5 \\
\hline 28 & $\begin{array}{l}\text { Are systems for communicating emergencies, e.g. intercom, loud speakers, telephones, siren, } \\
\text { etc. in working order? }\end{array}$ & 65.2 & 32.6 & 2.2 \\
\hline 29 & Is there a communication strategy between the office and staff? & 67.4 & 28.6 & 4.0 \\
\hline 30 & Are staff trained in First Aid and mouth-to-mouth resuscitation? & 28.9 & 68.9 & 2.2 \\
\hline 31 & Did all stakeholders draw up the school safety policy? & 37.6 & 59.7 & 3.4 \\
\hline 37 & Is there an education programme in security awareness? & 41.3 & 55.9 & 2.8 \\
\hline 42 & Are learners supervised at playgrounds? & 78.6 & 19.2 & 2.2 \\
\hline
\end{tabular}

Aspects like school safety committees, safety policies, reporting of violations of the law to the police and the Department and supervision of learners at playgrounds scored high positive responses. This implies that these aspects are in place at schools. However, these aspects can be viewed as something to be expected by virtue of their being policy requirements. For instance, school safety committees, safety policies and learner supervision are a requirement from the GDE. Therefore schools would be expected to have them, if only to be able to give account when required to do so. On the issue of the communication strategy between the office and staff, schools are bound to have such a strategy if only to facilitate the flow of information and instructions. However, four principals of town-suburban schools indicated confidently that their schools had management systems for safety and security. One, however, bemoaned the lack of adequate funds to ensure that all systems were implemented effectively. He commented that population dynamics of the school had so changed that the majority of parents could not afford fees that would make the implementation of systems viable and stated: "Despite that weakness, we and the SGB go all out to ensure we source funds for school security. For example, the communication systems for emergencies are in place and are a yearly budget priority".

Aspects that demonstrate that schools have formal, planned and well-coordinated activities aimed at school safety and security scored low percentage counts. These include, inter alia, incident registers to record disruptions and safety violations, training of staff to detect weapons, training in First Aid and mouth-to-mouth resuscitation, signage concerning visitor policy and trespassing, emergency teams to implement emergency plans, education programmes on security awareness and involvement of stakeholders in drawing the school safety policy. To this end, a principal of a township secondary school actually opined "I must be candid, some of these issues are just demanded by the department - we have to ensure that they are there, but, eh, implementing them is another story. Yes, plans are for the department - we do not really implement them. We do not have the resources to do so and also, the know-how is less than ideal". Another principal from a township primary school actually bemoaned the shortage of staff to carry out "all these functions". She stated: 
We have plans, policies and even the safety committee, but there isn't enough time to carry out all these functions. Teachers are overburdened with the new curriculum that changes every now and then. So, I try to fill the gaps on what has to be done, For example, my deputy and I respond, eh actually react to emergencies. Following the plan for emergencies is not possible. We do what we can.

The most glaring management aspects of school safety and security indicated negatively relate to whether there was an incident register where all disruptions and safety violations are recorded. This is an important measure in that it assists the school to identify safety-threatening trends and know when to focus on such incidents before they occur. Respondents indicated as such that disruptive incidents were not analysed to identify trends of common school safety problems. It was furthermore found that there was no signage in line with visitor policy and trespassing properly displayed at entrances to the schools. This seems exacerbated by the fact that the majority of respondents indicated that staff were not trained in detecting weapons. It became clear from responses that schools on the whole do not have coordinated safety plans. It is also clear that school safety considerations are not a collective effort. This implies that safety and security considerations reside in one person or a few people's functional domain(s). Therefore it can be surmised from these findings that management aspects at schools are not up to effective practical and functional standards. This does not, however, mean schools are unsafe. It alludes rather, to lack of coordinated activities and plans, especially with regards to safety and security awareness and consequently, preparedness. It was also found that in most cases, townsuburban schools had some form of emergency committees that dealt with issues around injuries on school grounds and classrooms and took care of learners who fell sick at school. In fact one primary school principal indicated that due to the lack of funds, they had to focus on "priorities, so that even if we are unable to cover all bases, at least the most crucial are taken care of. ... at this stage, I make sure that at least educators have basic knowledge and we focus on basic security concerns."

The second category explored how schools implemented surveillance and access control systems to ensure that the school campus and environment safety features were observable and visible and that safety measures related to this category were implemented. Data in this regard is illustrated in table 2.

Table 2: Data on the surveillance of and access control to the school environment

\begin{tabular}{|c|c|c|c|c|}
\hline Items & Questions & $\begin{array}{c}\text { Yes } \\
\%\end{array}$ & $\begin{array}{c}\text { No } \\
\%\end{array}$ & $\begin{array}{c}\text { Not sure } \\
\%\end{array}$ \\
\hline 10 & Is the main entrance always monitored? & 74.2 & 23.3 & 2.5 \\
\hline 11 & Do shrubs and trees allow good visual surveillance of all areas of the school? & 76.7 & 20.2 & 3.1 \\
\hline 13 & Is access to electrical boxes and connections restricted? & 73.9 & 24.3 & 1.8 \\
\hline 14 & Is the perimeter of the school properly fenced? & 85.8 & 12.4 & 1.8 \\
\hline 15 & Do all doors have locks that are in working condition? & 68.9 & 28.9 & 2.2 \\
\hline 17 & Is there regular surveillance/ monitoring of all school areas? & 48.1 & 50.3 & 1.6 \\
\hline 18 & Is the visitors' parking clearly demarcated and marked? & 32.3 & 66.1 & 1.6 \\
\hline 19 & Is the visitors' parking as close to the main office as possible? & 64.0 & 34.5 & 1.5 \\
\hline 20 & Can parking areas be monitored by school staff? & 46.6 & 50.7 & 2.7 \\
\hline 21 & Are entrances and exits clearly demarcated and marked? & 42.9 & 55.0 & 2.1 \\
\hline 22 & Are toilets easily accessible and visible to staff? & 90.4 & 8.4 & 2.2 \\
\hline 24 & Are there procedures for dealing with unauthorized persons on school property? & 56.2 & 41.6 & 2.2 \\
\hline 23 & Do visitors have to report to the office? & 95.3 & 3.1 & 1.6 \\
\hline 25 & Are signs concerning visitor policy and trespassing properly displayed at entrances to the school? & 28.0 & 70.3 & 1.9 \\
\hline
\end{tabular}

Responses to this category seemed to suggest that such measures were in place at most schools as indicated by the majority of positive responses to items above. It is remarkable that $85.5 \%$ of the respondents indicated that the perimeters of schools were properly fenced. This resonates with a finding in an earlier study where it was observed that schools had perimeter fencing made of both concrete and iron palisades (Xaba, 2006). It is also notable that most basic features of safety and security are in place at schools, including safe lockable doors, restricted access to electrical boxes and connections, monitoring of the main entrance to schools, visitor parking being close to the main office, visible and accessible toilets and good visual surveillance of all areas of schools. It is, however, worrisome that a numbers of safety measures seemed not to be implemented. For example, most respondents (50.3\%) indicated that there was no regular surveillance of all school areas, even though the main entrance to the school was monitored. The latter was found to be so because the Department had commissioned the employment of community members to monitor entrances to schools. A principal from a township secondary remarked: 
Since the employment of the security personnel at our school, we have seen a reduction in cases of vandalism and theft to electrical fittings. The only problem is at night where we do not have adequate or trained security people, resulting in the burglary of offices containing expensive technological stuff like computer boxes, although this has subsided immensely.

Another measure not effectively implemented was ensuring that visitor parking is clearly marked and demarcated and that staff monitor parking areas. This is an important omission in surveillance measures at schools because this is where intruders can easily gain access to a school and its occupants as well as possibilities of hijackings and abductions especially during quite periods. Furthermore, it is a critical non-implementation factor for more than half of the respondents (55\%) to indicate that entrances and exits are not clearly demarcated and marked. This could breach a school's safety and security in that in cases of emergencies, outside help could be delayed and impeded by uncontrolled people movement. Furthermore, intruders might find it easy to use exits as points of entry especially if these are not monitored. This could be compounded by the finding that a significant number of respondents (41.6\%) indicated that there were no procedures for dealing with unauthorized persons on school property, which is a serious breach of safety and security. This can even be more unsafe and hazardous considering that the majority of the respondents (70.3\%) indicated that there were no signs regarding visitation and trespassing policies displayed at school entrances.

While these are real concerns, I observed when visiting principals, that a number of schools had done a lot to ensure adequate access control including channelling visitors, through fencing, to the administration buildings. This resonates with the $95.3 \%$ of the respondents who indicated that visitors report to the office. This, however, was not complemented by ensuring that landscaping also did not obstruct surveillance to remote unoccupied areas of the schools, especially in township schools of the old buildings design where toilets for learners were set apart from classrooms (see Xaba, 2006, p. 577).

The third category (Table 3 data) investigated the safety and security measures with regard to service systems and practices. These include emergency systems, electrical systems and measures for handling the carrying of dangerous weapons.

Table 3: Data on service systems and practices

\begin{tabular}{clcc}
\hline \multirow{2}{*}{ Items Questions } & Yes & No Not sure \\
\cline { 2 - 3 } & $\%$ & $\%$ & $\%$ \\
\hline 3 & Do learners and staff know what to do in cases of emergencies like: & 49.458 .8 & 2.8 \\
3.1 & Fire? & 38.258 .7 & 3.1 \\
3.2 & Intruders/trespassers? & 22.773 .0 & 4.3 \\
3.3 & Armed robberies? & 44.152 .2 & 3.7 \\
3.4 & Electric faults and failures? & 15.881 .7 & 2.5 \\
4 & Are emergency drills/exercise held regularly to test the effectiveness of the school emergency plans? & 42.955 & 2.1 \\
8 & Are there procedures for handling problems regarding weapons at school? & 25.871 .7 & 2.5 \\
26 & Is there an emergency team organized to implement emergency plans? & 52.945 .4 & 1.7 \\
27 & Is there an individual assigned to be responsible for overall service systems and security procedures? & & \\
\hline
\end{tabular}

All but one item relating to safety systems and practices scored a low frequency count. Of main concern is the fact that procedures for emergencies seem not to be implemented or at least are not effectively implemented. Most concerning is the fact that the kinds of responses to emergencies like fire, intruders, armed robberies seem generally not to be known and therefore not effectively implemented in most instances. On fire extinguishers, a primary school principal indicated that mostly he was forced to handle emergencies as they were reported to him. He stated: "Look, so-called SSC is there on paper, not functional, despite attending meetings and workshops. Besides, ever since these fire extinguishers were installed, we have not been taught how to use them, and again they have never being serviced. So we do not know if they can still extinguish any fire. We actually rely on some male teachers who seem to know how to use them. Fortunately, we've not had a fire here at school".

This is also compounded by the fact that respondents, just like they indicated about weapon detection, indicated that there were no procedures for handling problems regarding weapons at schools. Drill exercises to test the effectiveness of emergency procedures were scored at $15.8 \%$ which indicates that they are generally not practiced. Generally it was found that emergency readiness was not appropriately catered for. For example, a township primary school principal commented that they "... react to crises as they happen". Another town-suburban secondary school 
principal expressed a sentiment suggesting that there were "no serious crisis situations here. Otherwise learners know they must listen to us. So if there is one, we'll tell them what to do". One township primary school principal admitted to having no systems for emergency readiness and stated: "This is something that we have never thought of as a staff and indeed such things do happen and there is no plan in place" while another principal from a township school commented "Oh! To be honest with you sir, nobody in our staff ever thought about safety measures in case of an emergency and thanks for the brilliant question, I'll share it with colleagues".

It can be concluded from the responses above, including comments from principals regarding service systems and practices, that not much consideration has been endowed to appropriate emergency response measures. Indeed this is cause for concern when considering that these measures are necessary for dealing with unforeseen and unplanned safety threats.

The last category (Table 4 data) sought to find out how schools implement safety measures with regard to the psychosocial environment.

Table 4: Data on the psychosocial environments of schools

\begin{tabular}{|c|c|c|c|}
\hline \multirow[t]{2}{*}{ Items } & Questions & Yes No & $\begin{array}{l}\text { Not } \\
\text { sure }\end{array}$ \\
\hline & & $\% \%$ & $\%$ \\
\hline 32 & Is corporal punishment completely eliminated from your school? & 56.540 .4 & 3.1 \\
\hline 35 & Are there procedures for handling incidents of physical abuse? & 66.831 .3 & 1.9 \\
\hline 36 & Are there known procedures for dealing with bullying? & 65.832 .0 & 2.2 \\
\hline 38 & Are there trained counsellors or teachers available for troubled learners? & 36.361 .2 & 2.5 \\
\hline 39 & Is there an education programme for dealing with substance abuse? & 34.862 .7 & 2.5 \\
\hline 40 & $\begin{array}{l}\text { Is there diversity training to encourage an understanding with those of other races, gender, cultures } \\
\text { and sexual orientation? }\end{array}$ & 36.661 .5 & 1.9 \\
\hline 41 & Are there programmes to help prevent sexual violence? & 38.558 .4 & 3.1 \\
\hline 43 & Is peer mediation for learners used? & 35.161 .8 & 3.1 \\
\hline
\end{tabular}

The most glaring poorly implemented safety and security measure concerning the psychosocial environment relates firstly to the use of corporal punishment. While the majority of respondents (56.5\%) indicated that corporal punishment was completely eliminated from their schools, a sizeable number (40.4\%) indicated that it had not. Secondly, it seems that teachers at these schools are not trained to deal with troubled learners. Thirdly, there does not seem to be adequate attention paid to education programmes for dealing with issues related to substance abuse. Fourthly, there is not enough attention paid to diversity training to deal with issues related to cultural, race and sexual orientation. Fifthly, there does not seem to be much attention paid to prevention of sexual violence and finally, peer mediation as a measure to deal with psychosocial challenges seems not to be practiced. Principals generally indicated lack of time and workloads as factors preventing the implementation of such measures. A township primary school principal indicated for instance, that they were "hamstrung by huge workloads for teachers, which makes it impossible to attend to such issues". Another principal of a township primary school remarked that teachers found it tedious to use alternative measures to corporal punishment, especially "... in this culture of children's rights, So they find it easy to 'steal' themselves and deal with misdemeanours quickly and I might add, effectively, by applying the stick. Though I must say we are all aware that it is illegal". A townsuburban secondary school principal referred to lack of time to pursue all these "useful, but tedious measures". Another principal from a town-suburban primary school bemoaned what he termed "lack of protection for educators" because the law seemed to mind the rights of "misbehaving learners, over the rights of the rest of the school". He continued showing sadness:

You see Sir, when you conduct things like body searches for drugs and illegal substances, parents sometimes take you to task for violating their children's rights to the so-called dignity. They make sure that they find something that will indicate a violation or non-compliance to legal procedures. So while these can be done, we are afraid of being charged in courts and appearing on first pages of newspapers. And once that happens, the Department descends on you ruthlessly to protect its image. But we sometimes have to act at the nick of time. Where do you get the time to follow the $A-Z$ of the law?

The affirmative responses to the items in this category indicate that schools do handle and deal with issues pertinent to their psychosocial environments. However, the negative responses point to what appears to be amiss: formally coordinated systems to deal with psychosocial aspects of the school environment. Clearly, schools should focus on 
formalising attempts to facilitate advocacy and sensitivity to these issues as well as ensure that there is stakeholder involvement in designing solutions to problems associated with these aspects.

\section{Discussion and Conclusion}

An analysis of responses to questionnaire items and views expressed by principals indicate overall, that safety and security measures at school are not implemented effectively. What is noticeable is that there are attempts at making schools safe and secure, but these are not systematic. Although it can be said that there are organisational structures like school safety committee and policies, these are not fully functional. Consequently, safety and security threats, emergencies and crises are reacted to as they occur. Clearly then, schools seem vulnerable and open to safety threats, both as a results of factors in the physical and the psychosocial environments. Indeed, this provides possible reasons for the proliferation of injuries at schools and often-reported incidents of bullying and fights at schools.

While it seems that safety and security measures are not effectively implemented, schools where some measures are implemented seem to enjoy relative safety and few incidents that threaten staff and learners. In fact a principal from a town secondary school pointed out that "... although our safety committee is not fully functional, we have made sure that we monitor the school campus carefully and have installed metal-detectors. As a result, we have had no incidents involving, for instance the carrying and use of weapons for the past four years". A principal of a township primary school commended their erection of channelling fences as having helped to reduce incidents of people or intruders going directly to the classrooms. She commented: "Since we erected fences that channel visitors from the main gate to the administration block, we do not have people invading classrooms without the office knowing. Now, everybody reports to the administration building and can't go anywhere in the school". This is a typical example of effectiveness of access control.

Safety and security measures are a must for every school. Therefore it is important for schools to adhere to the basics. Adherence to legislation is a good starting point because doing so informs best practices in school safety and security. The establishment of safety committees and the appointment of safety officers or coordinators must be followed by training in the basics of school safety and security. This is the responsibility of the provincial departments of education and district officials designated to school safety and infrastructure. It is of utmost importance to supplement schools' safety and security activities with monitoring mechanisms that will ensure the implementation of safety measures. For example, district officials responsible for this function must be seen to monitor and support schools. Seeing as safety and security are functions located in the governing bodies' domain, schools' strategic development planning should have safety and security as one of the pillars of school functionality and should be strategically planned for.

Although this study has shed light on the effectiveness of the implementation of school safety and security measures, the majority of schools surveyed were townships schools and therefore the findings may largely show bias towards these schools. It would help further to conduct a study of town-suburban schools only to determine the safety and security statuses, mainly because learners at these schools are mostly from townships.

Although the study covered the dimensions of safety and security as extensively as possible, it is by no means comprehensive because the scope of safety and security is so broad that not all dimensions could be addressed. For instance, natural surveillance and access control are themselves safety and security areas that can be studied separately. This is the limitation of this study. However, the data collected and insights garnered from participants do provide a holistic picture of the effectiveness of the implementation of safety and security measures at schools. The individual categories do open up scope for research in the area of safety and security.

\section{References}

American Clearinghouse on Educational Facilities. (Undated). Crime prevention through environmental design (CPTED). Tarleton State University: ACEF.

Brunner, J. \& Lewis, D. (2005). School safety's top ten. Principal Leadership, May. [Online] Available: http://www.findarticles.com/p/ articles/mi_qa4002/is_200505/ai_n13637067. (January 13, 2009).

Delport, C.S.L. (2002). Quantitative data collection methods. In A.S. De Vos (Ed.), Research at grassroots levels. For the social sciences and human service professionals. (pp. 165 - 196). Pretoria: Van Schaik.

Department of Education. (2001). South African Schools Act No. 84 of 1996. Regulations for the safety measures at public schools. Notice 1040. Government Gazette No. 22754. Pretoria: Government Printers.

Department of Education. (2006). South African Schools Act 84 of 1996. Amendment: regulations for safety measures at public schools. Gazette No. R1128. Pretoria: Government Printers.

Department of Education. (2007). South African Schools Act 84 of 1996. Regulations for safety measures at public schools. Education 
Laws Amendment Act No 31 of 2007. Government Gazette No. 30637. Pretoria: Government Printers.

Desyllas, J., Connoly, P. \& Hebbert, F. (2003). Modelling natural surveillance. Environment and Planning B: Planning and Design. 30, 643-655.

Florida Department of Education. (1993). Safe school design guidelines. Florida: The Florida Centre for Community Design + Research.

Hanover Research. (2013a). School Fencing: Benefits and Disadvantages. Washington, DC: Hanover Research District Administration Practice [Online] Available: http://www.hanoverresearch.com (Accessed 12 August 2014)

Hanover Research. (2013b). Best practices in school security.

Hanover Research District Administration Practice. [Online] Available: http://www.hanoverresearch.com/2013/05/best-practices-inschool-securityl. (October 13, 2013).

Ivancovic, N.V., Creswell, J.W. \& Plano Clark, V.L. 2007. Foundations and approaches to mixed methods research. In K. Maree (Ed.), First steps in research. (pp. 253 - 282). Pretoria: Van Schaik.

Leedy, P.D. \& Ormrod, J.E. (2005). Practical research. Planning and design. Upper Saddle River, N.J.: Pearson Merril Prentice Hall.

Masitsa, M.G. (2011). Exploring safety in township secondary schools in the Free State province. South African Journal of Education, 31,163-174.

McMillan, J.H. \& Schumacher, S. 2006. Research in education. Boston: Pearson Education.

Naidu, A., Joubert, R., Mestry, R., Mosoge, J. \& Ngcobo, T. (2008). Education management and leadership: A South African perspective. Cape Town: Oxford University Press.

Nyman, D. \& Levitt, J. 2006. Maintenance planning, scheduling \& coordination. New York, NY. Industrial Press Inc.

Public Schools of North Carolina State Board of Education. 2013. Environmental control and school size: Safe school facilities planner, health and life safety, school climate and order. Raleigh, NC.: Department of Public Instruction Safe and Healthy Schools Support Division - School Planning.

Republic of South Africa. (1996a). The Constitution of the Republic of South Africa. Act 108 of 1996, as adopted on 08 May 1996 by the Constitutional Assembly and amended by the Constitution of the Republic of South Africa Amendment Act, 1997 (Act No. 35 of 1997).

Republic of South Africa. (1996b). South African Schools Act, No. 84 of 1996. Cape Town: President's Office.

San Diego County Office of Education. (2003). Crime prevention through environmental design: How can it make your school safe? [Online] Available: http://www.sdcoe.net/cpted/cpted.asp. (May 05, 2006).

Scandinavian Schools of Brussels. (Undated). Psychosocial school environment. [Online] Available: http://www2.ssb.be/teachers/Publicl Plans/Psychosocial\%20School\%20Environment.pdf. (August 16, 2014).

Schneider, T. (2001). Safer schools through environmental design. ERIC Digest, 144. Jan.

Schneider, T. (2010). CPTED 101: Crime prevention through environmental design - The fundamentals for schools. [Online] Available: http://files.eric.ed.gov/fulltext/ED511746.pdf. (October 13, 2013).

Struwig, F.W. \& Stead, G.B. (2007). Planning, designing and reporting research. Cape Town: Pearson Education, South Africa.

The Society of State Leaders of Health and Physical Education. (2014). Making the connection II: Health and safe school environment. [Online] Available: http://www.thesociety.org/programs-MTC-health-safe-schools.asp. (August 16, 2014).

Thomas, M. (2013). Addressing school security challenges with access control systems. [Online] Available: http://www.sourcesecurity. com/news/articles/co-9787-ga.9555.html. (October 13, 2013).

U.S. Consumer Product Safety Commission. (2010). Public playground safety handbook. [Online] Available: http://www.cpsc.gov //PageFiles/122149/325.pdf. (October 13, 2013).

UNESCO. (2004). What else can schools do to improve the school environment? Paris: UNESCO.

Western Cape Education Department. 2014. Guidelines on playground safety at public schools. Cape Town: WCED. [Online] Available: http://wced.school.za/comms/press/2014/Guidelines-PlaygroundSafety.pdf. (Accessed 16 August 2014).

Xaba, M.I. (2006). An investigation into the basic safety and security status of schools' physical environments. South African Journal of Education, 26(4), 565-580.

Xaba, M.I. (2014). A holistic approach to safety and security at schools in South Africa. Mediterranean Journal of Social Sciences. 5(17), 1580-1589. Sept. 